\title{
Descriptive study of sledding injuries in Canadian children
}

Francis Lee, Martin H Osmond, Chandra P Vaidyanathan, Teresa Sutcliffe, Terry P Klassen

\begin{abstract}
Objectives-(1) To describe the characteristics of sledding injuries presenting to a pediatric emergency department and (2) To describe the sledding environment that leads to childhood sledding injuries.

Setting-A pediatric hospital emergency department in Ottawa, Canada and identified sledding sites in the region.

Methods-All patients less than 18 years with sled related injuries were included. Questionnaires were completed gathering information on the sled operator, the sled, the sledding site, and the injury. Site visits were made to designated and nondesignated sledding hills in the Ottawa region to record data regarding sled operators, sleds, and the sledding environment.

Results-Ninety five patients were identified with sledding injuries and $81(85 \%)$ completed the questionnaire. The mean age was 9.9 years (range 8 months to 17 years). The majority were male $(63 \%)$. Most injuries occurred on non-designated sledding hills in the community $(70 \%)$. Mild to moderate injuries were most common, however nine patients $(11 \%)$ were admitted to hospital. Fifty one per cent had adult supervision at the time of injury compared with $86 \%$ observed at the site visits. Common mechanisms of injuries were collisions with objects $(33 \%)$, falls in icy conditions (28\%), and going off jumps $(16 \%)$. Most serious injuries occurred with contact with motor vehicles. There was no relationship between the type of sled used and the likelihood of injury.

Conclusions-Sledding hills which have obstacles, icy conditions, jumps, or proximity to roads may result in more childhood injuries. Children with no adult supervision are likely at higher risk of injury.

(Injury Prevention 1999;5:198-202)
\end{abstract}

Keywords: sledding; tobogganing

Sledding is a popular winter recreational activity world wide for children who live in areas with lots of snow and long winters. It has been estimated that each winter $75 \%$ of children participate in at least one snow related sport such as tobogganing, skiing, or snowboarding. ${ }^{1}$ A search of the Canadian Hospitals Injury Reporting and Prevention Program (CHIRPP) database revealed 806 records of sled related injuries presenting to the participating emer- gency departments in the winter of 1995 ( 1 November 1994 to 30 April 1995). Of these, $11.1 \%$ were admitted to the hospital for treatment: twice the percentage of all injuries in the CHIRPP database that resulted in hospital admission $(5.7 \%)$. In the United States, sled related injuries are common, with approximately 33000 injuries each year that require emergency department care. ${ }^{2}$

Most of the studies on sledding injuries are retrospective. ${ }^{3-7}$ They describe the types of injuries seen in the emergency department and number of admissions to hospital, but are limited to only the information recorded in the emergency record. Hence, they document well the morbidity and mortality related to sledding but are unable to provide sufficient information on factors potentially related to injury, such as sledding hill conditions, type of sled used, parental supervision, or sledding behaviors.

There are two published prospective sledding injury studies $^{89}$ and one case-control study. ${ }^{10}$ These studies have identified a number of factors that may be related to sledding injuries, including type of sled, ${ }^{8} 10$ sledding in streets, ${ }^{9}{ }^{10}$ lack of adult supervision, ${ }^{10}$ and type of hill (designated versus non-designated). ${ }^{89}$ ("Designated hills" are those hills that the community has officially set aside specifically for sledding. They are usually posted as such, are free of obstacles along the slope, have an adequate run-off area at the bottom of the hill, and protected uphill walkways. Nondesignated hills are all other public and private areas where children toboggan.) However, there is some doubt about the accuracy of some of the assertions made by these studies because the exposed population has not been evaluated.

In an attempt to further define factors related to sledding injury, we designed a study to: (1) describe the characteristics of sledding injuries presenting to a pediatric emergency department and (2) describe the sledding environment and possible hazards that may lead to childhood sledding injuries.

\section{Methods}

STUDY SETTING

The Children's Hospital of Eastern Ontario is a tertiary care pediatric hospital that has about 48000 emergency department visits per year. It is the only center to admit children in the Ottawa area and treats most pediatric orthopedic injuries.

\section{SELECTION OF PATIENTS}

All children (aged 0 to 17 years) who were seen at the emergency department with a sled
Road, Ottawa, Ontario,

Canada K1H 8L1 (e-m

osmond@cheo.on.ca). 
related injury during a winter season (December 1996 to March 1997) were eligible. This included injuries sustained by sled operators, passengers, or bystanders. We defined sledding as a recreational activity whereby a child uses any metal, wooden, or plastic device to transport him or herself down a snow covered hill. Patients were identified and enrolled by the triage nurse in the emergency department. A study nurse (TS) reviewed all emergency department charts to ensure that no patients had been missed during the study period.

\section{STUDY DESIGN}

Part 1 was a prospective descriptive study of all sled injured children. A specially designed questionnaire, as well as a consent form for subsequent telephone follow up, was given to all sled injured children or their parents when they registered in our emergency department. The questionnaire contained 22 questions to gather information on the rider (such as age, gender, riding habits, use of protective devices), the sled type, and the environment of the slope (such as snow conditions and presence of obstacles or jumps). It also asked open ended questions such as "Why do you think this injury happened ?". The questionnaires and emergency charts were collected and reviewed by the investigators. Specific injuries were recorded as well as their disposition from the emergency department (admitted or discharged). Inpatient records were reviewed for all admitted patients. Telephone follow up was made at five to seven days postinjury to all consenting patients/parents, at which time the status and severity of the injury were recorded. At this time any missing information on the questionnaire was obtained. A second phone call was made at three weeks post-injury if the patient had not returned to his/her normal activity at one week post-injury. For those who refused to consent for telephone follow up, only the injury data were included and no further attempt to contact the patient or parents was made.

Part 2 of the study involved site visits by the investigators throughout the winter to all designated sledding hills in the Ottawa region (as provided by the City of Ottawa municipal office). We also visited many commonly used non-designated sledding hills and some sites where injuries had occurred. During each visit, one of the researchers (FL or MHO) observed and recorded basic demographic data on the riders as well as details on the type of sleds used, sledding environment, and proportions of riders using any protective devices. The visits were performed on different days of the week and at different times of the day to give an even distribution of days and times.

\section{STATISTICAL ANALYSIS}

Data from the questionnaires were entered into a database created in SPSS/PC +V4.01 software (Statistical Package for the Social Science, SPSS Inc, Chicago). Continuous variables were reported as means and SDs. Categorical variables were presented as counts (\%). Intraclass correlation coefficients (ICC) were used to measure the level of interobserver reliability. An ICC value from 0.4 to 0.75 represents fair to good agreement, less than 0.4 poor agreement and greater than 0.75 excellent agreement. $^{11}$

\section{Results}

During the study period, 95 children with sled related injuries were seen in our emergency department. Of these, $81(85 \%)$ completed the questionnaires and $14(15 \%)$ chose not to participate. (Review of the emergency charts indicated that none of the refusers had significant injuries: two minor head injuries, eight soft tissue injuries, and four abrasions.) All of the 81 patients who returned their questionnaires consented to telephone follow up. However, we were only able to locate $71(88 \%)$ of them. The reasons for failed follow up included incorrect phone number (5), unable to make contact despite numerous phone calls (4), and a disconnected phone line (1).

Forty five visits were made to 20 different toboggan sites in the Ottawa-Carlton region during the study period. Nine different site visits were made by two investigators at the same time and on the same day to test interobserver reliability.

The following data summarize the characteristics of the sled injured patients and, where possible, gives a comparison between the sled injured patients and the children observed sledding at site visits (an estimate of the exposed population).

\section{RIDER CHARACTERISTICS}

The mean (SD) age of the injured patients was 9.9 (3.7) years, with a range of 8 months to 17 years, and there was a higher proportion of males $(63 \%)$. Fifty one per cent of our patients had adult supervision at the time of injury compared with $86 \%$ observed at the time of the site visits. None of the injured patients were using a helmet when the injury occurred, compared with $3 \%$ of sled riders and passengers observed during the site visits. Table 1 shows the age range and percentage of both the injured riders and the children observed at the site visits. Although 10-14 year olds accounted for only $19 \%$ of the children observed at the site visits, they represented $47 \%$ of all injured children. The ICCs between two observers at the site visits are also shown. None of the injured patients reported using alcohol or other drugs around the time of the injury.

VEHICLE CHARACTERISTICS

Table 2 shows the sled types used by the injured children and those observed at the site visits. Although GT racers were the most

Table 1 Age of sled riders

\begin{tabular}{lccc}
\hline $\begin{array}{l}\text { Age range } \\
\text { (years) }\end{array}$ & $\begin{array}{l}\text { Injured patients } \\
(\%)\end{array}$ & $\begin{array}{l}\text { Site visit children } \\
(\%)\end{array}$ & $I^{*}$ \\
\hline$<5$ & $7(9)$ & $110(21)$ & 0.09 \\
$5-9$ & $30(37)$ & $277(53)$ & 0.82 \\
$10-14$ & $38(47)$ & $99(19)$ & 0.64 \\
$>14$ & $6(7)$ & $37(7)$ & - \\
Total & $81(100)$ & $523(100)$ & \\
\hline
\end{tabular}

^Intraclass correlation between two observers at site visits. 
Table 2 Sled types of injured patients and site visit population

\begin{tabular}{llll}
\hline Sled type & $\begin{array}{l}\text { Injured } \\
\text { patients (\%) }\end{array}$ & $\begin{array}{l}\text { Site visit } \\
\text { children (\%) }\end{array}$ & ICC $^{*}$ \\
\hline GT racer & $22(27)$ & $134(26)$ & 0.94 \\
Plastic sled & $14(17)$ & $153(29)$ & 0.88 \\
Magic carpet & $14(17)$ & $93(18)$ & 0.52 \\
Flying saucer & $8(10)$ & $54(10)$ & 0.71 \\
Other & $11(14)$ & $89(17)$ & \\
None & $12(15)$ & - & \\
Total & $81(100)$ & $523(100)$ & \\
\hline
\end{tabular}

^Intraclass correlation between two observers at site visits.

Table 3 Location of sledding areas where injuries occurred

\begin{tabular}{lr}
\hline Location & No (\%) \\
\hline Designated sledding hill & $24(30)$ \\
Home yard & $12(15)$ \\
City park & $11(14)$ \\
Schoolyard & $10(12)$ \\
Other & $22(27)$ \\
Unknown & $2(2.5)$ \\
\hline
\end{tabular}

common sled used by injured children (27\%), they were also used by approximately the same percentage of children observed at the hills $(26 \%)$. There was also no difference between the percentage of children who were injured and those observed at the hills using either "magic carpets" or "flying saucers". Interestingly, the plastic sled was used by $29 \%$ of children observed at site visits but used by only $17 \%$ of injured children. The ICC for counting the number of different sled types varied from 0.52 to 0.94 .

ENVIRONMENTAL CHARACTERISTICS

Most injuries (87\%) occurred in the three months from December to February, with $44.4 \%$ in January, $22 \%$ in December, and $21 \%$ in February. Fifty eight per cent of injuries occurred during the weekends (Friday 25\%, Saturday $11 \%$, and Sunday $22 \%$ ). The most common time for injury was between noon and $5 \mathrm{pm}(59 \%)$. Twenty nine per cent of injuries occurred between the hours of $5 \mathrm{pm}$ and $7 \mathrm{am}$.

As shown in table 3 , only $24(30 \%)$ of the injuries occurred at designated sledding hills. Most $(70 \%)$ occurred in non-designated sledding areas such as city parks, schoolyards, homes, and other private properties.

The distribution of patients by the mechanisms of injury are shown in table 4. They include collision with an object (33\%), loss of control in icy conditions (29\%), going off jumps $(16 \%)$, and other mechanisms $(22 \%)$. Of the 24 children injured at designated sledding hills, nine $(38 \%)$ fell off a sled travelling too fast, six $(25 \%)$ collided into another sled, and four (17\%) were hit by a sled while standing up. The majority of patients and parents blamed icy/fast conditions as leading to the injury.

INJURY TYPES

Mild to moderate injuries were most common and included soft tissue injuries (38\%), fractures $(36 \%)$ (including five femur and two tibial fractures), minor head injuries $(12 \%)$, and lacerations $(10 \%)$. Serious injuries included one liver laceration, one basal skull fracture, one depressed skull fracture with
Table 4 Mechanism of injury

\begin{tabular}{ll}
\hline Mechanism of injury & No (\%) \\
\hline Collision with an object & $27(33)$ \\
Loss of control on ice & $23(29)$ \\
Going off a jump & $13(16)$ \\
Other & $18(22)$ \\
Total & $81(100)$ \\
${ }^{\star} 11 / 13(85 \%)$ were in $10-17$ year age group with a 3/13 (23\%) \\
adult supervision rate.
\end{tabular}

intracerebral hemorrhage, and one pelvic fracture with vaginal laceration. The latter two patients were injured by collisions with motor vehicles. Nine patients $(11 \%)$ were admitted to hospital.

OUTCOME AND PATIENT FOLLOW UP

Sixty eight patients (84\%) were discharged from the emergency department immediately after being treated. Three $(3.7 \%)$ required observation in the emergency department for several hours, and nine (11\%) were admitted, two to the intensive care unit. On follow up, 47 $(66 \%)$ of patients had returned to normal activity after one week and $54(76 \%)$ after three weeks. The $24 \%$ who had not returned to normal activity after three weeks were either immobilized in a cast or still in hospital.

\section{Discussion}

Our study confirms the findings of others that sled related injuries are a pediatric problem that results in a high percentage of sledding injured patients being admitted to hospital $(11 \%)$. Hospitalization rates in other studies have ranged from $9 \%$ to $24 \% .{ }^{6}{ }^{10}$ While this undoubtedly reflects a referral bias to tertiary care centers, it is significantly higher than the average hospitalization rate for all injuries that present to emergency departments $(5.7 \%)$ as reported by Health Canada from the CHIRPP database.

In this descriptive study, we have identified many factors that may be responsible for an increased risk of sled related injury. However, we are unable to quantify these with relative risk estimates because we did not have a cohort or case-control study design. Future studies may wish to use these study designs in order to quantify the relative risk estimates.

Although there were no fatalities in this study, we report two serious injuries as a result of sleds being hit by cars. These both occurred at non-designated sites. Other authors have also found sledding near roadways to result in severe injury. Rowe et al reported two deaths in children over a five year period in Ontario after their sleds were run over by cars as they ran out of their driveways into the street. ${ }^{12}$ Shugerman et al found a significant increase in risk of injury for children who sledded in streets versus those who sledded in a park (odds ratio $5.1 ; 95 \%$ confidence interval 1.1 to 24.1$){ }^{10}$

Males are injured more commonly than females in sled trauma. This has been a consistent finding throughout many previous studies. ${ }^{3568}$ We found a male predominance of $63 \%$ of injured children. Unfortunately, during our site visits we could not easily distinguish 
boys from girls because of their bulky winter clothing so we were unable to determine whether more boys are injured because of a higher exposure to sledding or because of a behavioral difference between boys and girls.

Interestingly, children under 5 years were observed to make up $21 \%$ of the site visit population but accounted for only $9 \%$ of the injured population. Conversely, children 10-14 years made up only $19 \%$ of the site visit population while they accounted for $47 \%$ of the injured population. These results could indicate that 10-14 year old sledders are at a relatively higher risk of injury while sledders less than 5 years old are at a lower risk. We hypothesize that parental supervision of the younger children may be responsible for their lower injury rate. However, this hypothesis cannot be proven by our study as we cannot be sure that our site visit population is completely representative of all sledding children in our region.

A large number of injuries (33\%) occurred when a sled struck a fixed object such as a tree, rock, or pole. In these cases, deceleration is immediate and the kinetic energy of the moving sled is rapidly absorbed by the rider's body, ${ }^{3}$ frequently leading to serious injuries such as fractures, visceral injuries, and head injuries. Previous studies have also cited this as a prominent mechanism of injury. ${ }^{8-10}$

Icy conditions played a large role in the injuries we observed. Twenty eight per cent were directly attributable to losing control on ice, while many other children cited high speed and inability to steer as a reason for the sled hitting an obstacle or another child. Sleds may reach speeds exceeding $35 \mathrm{~km}$ per hour ${ }^{7}$ depending on the slope of the hill. In icy conditions the speed is increased, and steering and stopping are compromised leading to difficulty in avoiding objects or other people on the slope. This has been reported by Landsman et $a \bar{l}$ and by Lewis et al..$^{13}$ Both found an increase risk of sledding injuries during icy conditions.

This is the first study to identify "jumps" as a risk factor for sledding injury. Thirteen children $(16 \%)$, mostly of adolescent age (10-14 years) and without adult supervision (10 or $77 \%$ ), reported their injury as being due to "going off a jump". Many hills visited had man made jumps at the bottom of the slope. It is easy to imagine how loss of control at high speed over a jump could lead to a significant impact and injury.

Our results suggest that sledding without adult supervision is also dangerous. We found that $49 \%$ of injured children had no adult supervision at the time of the injury, although we observed only $14 \%$ of children to have no adult supervision at the site visits. This finding is corroborated by Shugerman et al who found an increased risk of injury in those children who sledded without adult supervision (odds ratio $5.6 ; 95 \%$ confidence interval 1.1 to 26.9). ${ }^{10}$

Our study has also shown that protective gear is worn by very few sledders. Only 3\% of children were seen to be wearing helmets at the site visits. None of the injured sledders wore any protective gear. These findings are similar to those of Wynne et al who found helmet use in only $1 \%$ of injured sledders. ${ }^{8}$

\section{Limitations}

This study has some limitations. The site visits were an attempt to characterize the exposed population at risk for sledding injury. However, we recognize that this is not a true denominator as it represents only a small sampling of the total pediatric sledding population. In order to make it as representative as possible we visited many different types of hills, designated and non-designated, at different times of day. However, we have no data on those children sledding in their own home yard or other private properties which may account for a high percentage of sledding children.

Unfortunately, we were unable to recruit $15 \%$ of all the injured sledders that presented to our emergency department. Our chart review documented that these were mainly children with mild injuries.

\section{Implications for prevention}

The results of this study have important implications for prevention activities that may reduce injury in the sledding population.

\section{ENVIRONMENT}

A safe sledding site is central to reducing sled related injury. Safe sledding areas should be free of obstacles and have long clear run outs at the bottom of the hill to prevent collisions with obstructions. There should be an uphill walkway where children can safely return to the top of the hill. The hill should be kept free of potentially hazardous jumps, and the sledding site must be located away from roads and traffic. The site should close at dusk unless lighting is provided. The site must be inspected regularly and should be closed to the public if icy conditions are present.

We hypothesize that a well maintained and patrolled, designated sledding hill which provides all of these benefits should decrease the number of serious or fatal sledding injuries seen in our community.

\section{OPERATOR}

Unfortunately, even at a well designed sledding site injuries will still occur due to operator factors. It is intuitive that adult supervision is important for younger children to guide them to appropriate slopes that are not too steep or icy and are free from obstacles. Young children should be accompanied down the hill until they are old enough to steer, brake, and avoid collisions. However, for the older child (10-14 year olds) supervision is also important to help curb risk taking behavior, such as high speeds and hazardous jumps.

Because severe head injuries are frequently the cause of death in sledding trauma, ${ }^{12}$ there may be a role for helmet use to prevent these injuries. Helmet use may be limited because parents and children are unaware of the potential dangers of sledding, ${ }^{10}$ and because bicycle helmets, which many children own, do not fit 
well over winter hats. Hockey helmets may be a useful alternative as they provide good coverage, fit, head protection, and warmth for both children and adults.

VEHICLE

We found no particularly hazardous sled type in our study. It appears that it is where and how you use your sled that may be more important in injury prevention.

\section{PREVENTION STRATEGIES}

Municipal governments should be encouraged to develop and maintain well designed, sledding hills with safe sledding information readily available for parents. These hills should be regularly patrolled and closed if icy conditions exist.

Health information, perhaps in the form of a community-wide media campaign at the beginning of the winter, could help to prevent sledding injuries. Parents should be advised to accompany their child to the slope and choose an appropriate slope for the child. We believe that designated sledding hills should be endorsed and recommended by communities.

Currently, Plan-it Safe, the Child and Youth Injury Prevention Center at the Children's Hospital of Eastern Ontario in Ottawa, is launching a campaign to increase helmet use in all activities, including sledding, where serious head injury is possible.

We thank Ba' Pham, M Math, for his assistance with statistical analysis.

1 Senturia YD, Binns HJ, Christoffel KK, et al. In-office survey of children's hazard exposure in the Chicago area: agespecific exposure information and methodological lessons. fDev Behav Pediatr 1993;14:169-75.

2 US Consumer Product Safety Commission, Directorate for Epidemiology. NEISS data highlights. Washington, DC: CPSC, 1985: 9/1986:10/1987:11.

3 Hedges JR, Greenberg MI. Sledding injuries. Ann Emerg Med 1980;9:131-3.

4 Sloan JP, Maheson M, Dove AF. How dangerous is Sloan JP, Maheson M, Dove
sledding? BMf 1985;290:821.

5 Landsman IS, Knapp JF, Medina F, et al. Injuries associated Landsman IS, Knapp JF, Medina F, et al. Injuries associated
with downhill sledding. Pediatr Emerg Care 1987;3:277-80. 6 with downhill sledding. Pediatr Emerg Care 1987;3:277-80. injuries in children [letter]. Am $\mathcal{F}$ Dis Child 1990;144:10713.

7 Manary MJ, Hollyfield Jr WC. Childhood sledding injury in 1990-1991. Pediatr Emerg Care 1993;9:155-8.

8 Wynne $\mathrm{AD}$, Bota $\mathrm{GW}$, Rowe $\mathrm{BH}$. Sledding trauma in a northern Ontario community. F Trauma 1994;37:820-5.

9 Bjornstig U, Tordai P. Tobogganing and sledging accidents. Scand F Soc Med 1986;14:83-6.

10 Shugerman RP, Rivara FP, Wolf ME, et al. Risk factors for childhood sledding injuries: a case control study. Pediatr Emerg Care 1992;8:283-6.

11 Fleiss JL. The design and analysis of clinical experiments. New Fleiss JL. The design and analysis

12 Rowe BH, Bota GW. Sledding deaths in Ontario. Can Fam Rowe BH, Bota GW. Sled
Physician 1994;40:68-72.

13 Lewis LM, Lasater LC. Frequency, distribution, and management of injuries due to an ice storm in a large metropolitan area. South Med F 1994;87:174-8.

Four boys aged 13-17 years were burned in separate incidents after cigarettes were lit while they were sniffing paint thinner. The authors report that the boys were "socially deprived and neglected", and had school learning and relationship difficulties. Thus hospital treatment for their burn injuries provided an excellent opportunity to address their other problems (Burns 1998;24:757-9).

A 9 month old infant was seated in a forward position instead of backwards in a rearwardfacing infant restraint when the motor vehicle she was travelling in was involved in a head-on collision. Rapid deceleration may have caused the infant to flex and "submarine" under the lap belt, resulting in compression and laceration of her liver. She also lacerated her tongue. The purpose of the rearward-facing position is to distribute the deceleration forces over a large part of a child's body and to provide spinal support; these restraints need to be positioned correctly for maximum effectiveness (Fournal of Trauma 1998;45:838-40).

A 2.5 year old boy seated on his mother's lap, and in the same seat belt, sustained severe abdominal trauma from the force applied to his abdomen at the moment of impact when he was involved in a high speed motor vehicle collision. Two passengers in the same seat belt don't work (Pediatric Emergency Care 1998;14:352-3).

After being thrown from a go-kart on which he was a passenger and hitting his head, a 7 year old boy was found to have a perforated bowel. When he presented to the emergency department with facial trauma, this could have disguised the more serious abdominal problem had the physicians been less persistent in their investigations (Pediatric Emergency Care 1998;14:441-3).

A Colorado study of 51 cases of injuries in driveways found a 10-fold increase in mortality in children under 5 years of age when compared with all other pediatric pedestrian accidents (Fournal of Pediatric Surgery 1998;33:1712-15).

It's sometimes difficult to know what to package in child resistant containers and what not to. Reading the case reports of two boys aged 21 and 30 months sustaining chemical burns to the airway, gastrointestinal tract, or skin after ingesting or spilling artificial nail primer, it's easy to say the containers should have been fitted with child resistant closures, yet few cases of this type have been reported. These particular containers were not fitted with child resistant closures, nor did they have information about toxicity on the packaging (Pediatrics 1998;102:979-84). 